\title{
Reliability Modeling of Complex Electronic System Based on Weibull Distribution
}

\author{
Linying Wei*, Weilu Wu and Jun Xu \\ Hefei City, Anhui Province, China \\ ${ }^{*}$ Corresponding author
}

\begin{abstract}
The failure law is not clear in operation of complex electronic system. The failure data can not be effectively used. And it is difficult to assess the current state of the system. This paper proposed a fitting method of failure data based on triple Weibull distribution model for complex repairable long-life-cycle complex electronic system. Triple Weibull modeling method is used to analyze the accumulated operation time of complex electronic system. Maximum likelihood estimation is used to estimate the shape and scale parameters in Weibull distribution. And the specific iterative solution process is given. Using function continuity, the formula for the corresponding triple Weibull distribution is derived.And the key time inflection points and connection parameters are given. The failure data of electronic warfare system is used to analyze and verify the feasibility of the method.
\end{abstract}

Keywords-triple Weibull distribution; bathtub curve; complex electronic system; failure law analysis

\section{INTRODUCTION}

Complex electronic system is composed of many electronic devices. During the life cycle of the complex electronic system, the system failure data contains the important information of system reliability, providing data support for assessing the current status of system and predicting the probability of failure[1]. Therefore, studying the fault data of complex electronic system has important application value and practical significance.

In general, reliability data comes mainly from reliability experiments. Reliability experiments are mainly performed by manufacturers during the manufacturing process[2].Since the life of the system is generally long, the reliability experiments conducted by the R\&D unit and the manufacturer cannot predict the reliability of the system in simulation use. They can only give a reference data that reflects reliability. Therefore, the reliability status of the system used in the operation process needs to be evaluated and predicted using the data in the operation of the system[3] .

The fault data in the operation process of complex electronic system is studied. The data in Table 1 is the statistical data obtained from the simulation of operational failure data.A total of 65 sets of fault data are used to fit the probability density function with the frequency of faults in the system operating time range. the fault occurrence time is grouped every 200 hours. The number of faults over a period of time, the frequency of the faults, and the current cumulative frequency of the faults are shown in table1.
TABLE I. FAULT DATA SHEET

\begin{tabular}{|c|c|c|c|}
\hline \multirow[b]{2}{*}{ Runtime range } & \multicolumn{3}{|c|}{ The statistical data } \\
\hline & $\begin{array}{l}\text { Number } \\
\text { of failures }\end{array}$ & frequency & $\begin{array}{c}\text { Current } \\
\text { cumulative } \\
\text { frequency }\end{array}$ \\
\hline $500 \mathrm{~h} \sim 700 \mathrm{~h}$ & 6 & 0.0857 & 0.0857 \\
\hline 700h 900h & 4 & 0.0571 & 0.1429 \\
\hline $900 \mathrm{~h} \sim 1100 \mathrm{~h}$ & 3 & 0.0429 & 0.1857 \\
\hline $1100 \mathrm{~h} \sim 1300 \mathrm{~h}$ & 4 & 0.0571 & 0.2429 \\
\hline $1300 \mathrm{~h} 1500 \mathrm{~h}$ & 3 & 0.0429 & 0.2857 \\
\hline $1500 \mathrm{~h} \sim 1700 \mathrm{~h}$ & 1 & 0.0143 & 0.3 \\
\hline 1700h 1900h & 1 & 0.0143 & 0.3143 \\
\hline 1900h 2100h & 3 & 0.0429 & 0.3571 \\
\hline $2100 \mathrm{~h} \sim 2300 \mathrm{~h}$ & 2 & 0.0286 & 0.3857 \\
\hline $2300 \mathrm{~h} \sim 2500 \mathrm{~h}$ & 3 & 0.0429 & 0.4286 \\
\hline $2500 \mathrm{~h} \sim 2700 \mathrm{~h}$ & 1 & 0.0143 & 0.4429 \\
\hline $2700 \mathrm{~h} \sim 2900 \mathrm{~h}$ & 2 & 0.0288 & 0.4714 \\
\hline 2900h 3100h & 1 & 0.0143 & 0.4857 \\
\hline $3100 \mathrm{~h} 3300 \mathrm{~h}$ & 1 & 0.0143 & 0.5 \\
\hline $3300 \mathrm{~h} 3500 \mathrm{~h}$ & 2 & 0.0286 & 0.5286 \\
\hline $3500 \mathrm{~h} \sim 3700 \mathrm{~h}$ & 3 & 0.0429 & 0.5714 \\
\hline $3700 \mathrm{~h} \sim 3900 \mathrm{~h}$ & 1 & 0.0143 & 0.5857 \\
\hline 3900h 4100h & 1 & 0.0143 & 0.6 \\
\hline $4100 \mathrm{~h} \sim 4300 \mathrm{~h}$ & 2 & 0.0286 & 0.6286 \\
\hline $4300 \mathrm{~h} \sim 4500 \mathrm{~h}$ & 3 & 0.0429 & 0.6714 \\
\hline $4500 \mathrm{~h} \sim 4700 \mathrm{~h}$ & 3 & 0.0429 & 0.7143 \\
\hline $4700 \mathrm{~h} \sim 4900 \mathrm{~h}$ & 4 & 0.0571 & 0.7714 \\
\hline 4900h 5100h & 4 & 0.0571 & 0.8286 \\
\hline $5100 \mathrm{~h} \sim 5300 \mathrm{~h}$ & 6 & 0.0857 & 0.9143 \\
\hline $5300 \mathrm{~h} \sim 5500 \mathrm{~h}$ & 6 & 0.0857 & 1 \\
\hline
\end{tabular}

The fault frequency is plotted, as shown in Figure 1. It can be seen that the frequency of failures firstly decreases, then tends to be stable, and lastly increases again. The accumulated frequency of failures generally shows a rapid increase first, then a slow increase, and a rapid increase in the last. Therefore, the distribution obeyed by the system failure will not be a normal distribution or a log-normal distribution, but may be an exponential distribution or a Weibull distribution. Therefore, it is speculated that failure rule of complex electronic system may obey the Weibull distribution. 


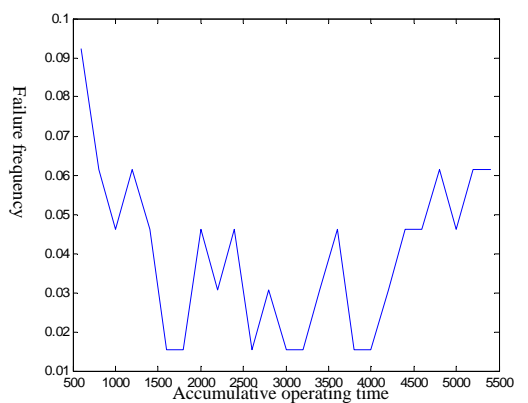

FIGURE I. TREND CURVE OF FAILURE FREQUENCY

\section{SYSTEM RELIABILITY MODEL ESTABLISHMENT AND CASE ANALYSIS}

The Weibull probability plot is used to test whether the data obeys the Weibull distribution. When the data obeys the Weibull distribution, the data appears linear in the Weibull probability plot, otherwise it appears nonlinear. The principle is to transform Weibull distribution function, and then take twice logarithm operations on both sides, so as to present the linear relationship. Weibull probability plots are plotted using the accumulated operation time data of 65 sets of failures, as shown in Figure 2.

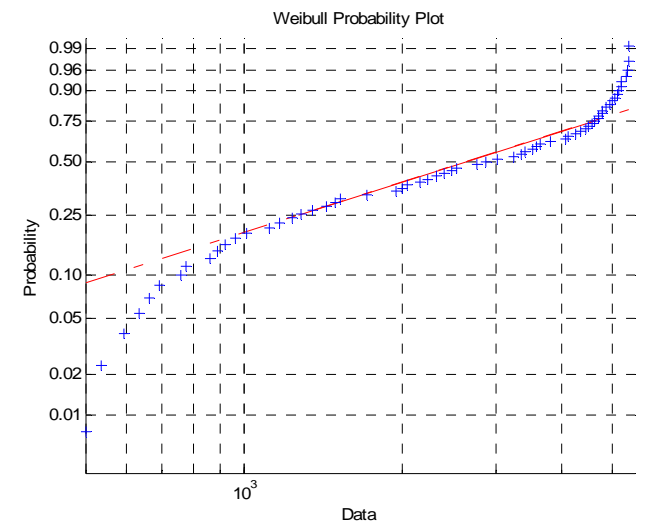

FIGURE II. WEIBULL PROBABILITY PLOT OF 65 SETS OF DATA

As shown in the Figure 2, the 65 sets of data are not in a straight line and are clearly divided into three processes. We can use the triple Weibull segmented model to fit the system failure data.

\section{A. Triple Weibull Model}

The system failure generally follows a regular pattern and will go through three periods: early failure period, accidental failure period, and loss failure period[4]. The early failure period is due to defects and quality problems in the internal modules and components of the system. The accidental failure period happens when the failure probability of the system tends to be a steady low level after defects and quality problems of components or modules are repaired, and each module or component enters the optimal operation state. Loss failure period is because of the time and environmental stress and the aging of modules and components. Probability of failure will gradually increase. The probability of system failure changes with time, showing a decrease process in the first period, then a steady process in the middle period, a increase process in the last period, as a form of a curve similar to the "bathtub". It was called bathtub curve in system reliability study[5-7].

The Weibull distribution is one of the commonly used distributions in reliability studies. In order to accurately represent the three stages corresponding to the bathtub curve, the bathtub curve distribution can be constructed using the Weibull distribution in the form of a piece-wise function.The expression of the triple Weibull distribution function, the reliability function expression and the corresponding failure rate function are as follows:

$$
\begin{gathered}
F(t)=\left\{\begin{array}{l}
1-k_{1} \exp \left[-\left(t / m_{1}\right)^{n_{1}}\right], 0<t<t_{1} \\
1-k_{2} \exp \left[-\left(t / m_{2}\right)^{n_{2}}\right], t_{1}<t<t_{2} \\
1-k_{3} \exp \left[-\left(t / m_{3}\right)^{n_{3}}\right], t>t_{2}
\end{array}\right. \\
R(t)=1-F(t)=\left\{\begin{array}{l}
k_{1} \exp \left[-\left(t / m_{1}\right)^{n_{1}}\right], 0<t<t_{1} \\
k_{2} \exp \left[-\left(t / m_{2}\right)^{n_{2}}\right], t_{1}<t<t_{2} \\
k_{3} \exp \left[-\left(t / m_{3}\right)^{n_{3}}\right], t>t_{2}
\end{array}\right. \\
h(t)=-\frac{d}{d t} \ln R(t)=\left\{\begin{array}{l}
\frac{k_{1} n_{1}}{m_{1}}\left(t / m_{1}\right)^{n_{1}-1}, 0<t<t_{1} \\
\frac{k_{2} n_{2}}{m_{2}}\left(t / m_{2}\right)^{n_{2}-1}, t_{1}<t<t_{2} \\
\frac{k_{3} n_{3}}{m_{3}}\left(t / m_{3}\right)^{n_{3}-1}, t>t_{2}
\end{array}\right.
\end{gathered}
$$

In these formulas, $n_{1}, n_{2}, n_{3}$ is the shape parameter of each segment function. $m_{1}, m_{2}, m_{3}$ is a scale parameter of each segment function. $k_{1}, k_{2}, k_{3}$ is the connection parameter for each segment function. $t_{1}, t_{2}$ is the function demarcation point. In the system failure analysis, different $n$ represents different failure mechanisms. When $n<1$, the system is in an early failure period. When $n$ is approximately 1 , the system is in an accidental failure period. When $n>1$, the system is in a loss failure period.

\section{B. Triple Weibull Probability Plots Test}

The first 20 sets of data, 21-42 sets of data, and 43-65 sets of data are tested by Weibull probability plots. All these tests can show a good linear relationship. The Weibull probability plot is shown in Figure 3(a),(b),(c) 


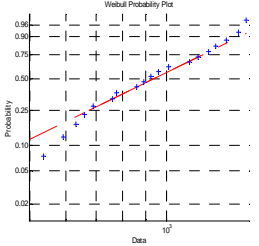

(a)

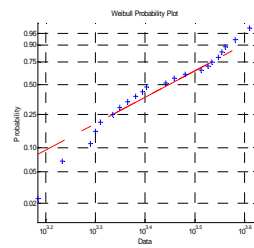

(b)

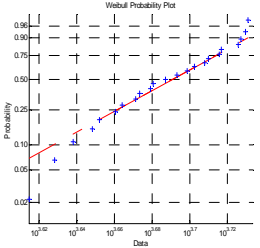

(c)
FIGURE III. WEIBULL PROBABILITY PLOT FOR EACH GROUP OF DATA

\section{Weibull Distribution Parameter Estimation}

According to the results of the Weibull probability plot test, 65 sets of data were separately fitted. The Weibull parameter estimation was performed on the first 20 sets of data, the middle 22 sets of data, and the last 23 sets of data, and the parameters were calculated using the maximum likelihood estimation method[8-9].Result of parameter estimation is shown in equation (4).

$$
\left\{\begin{array}{l}
m=\left[\frac{\sum_{i=1}^{a} t_{i}^{\frac{1}{n}}}{a}\right] \\
\frac{a}{n}-a \ln (m)+\left[\sum_{i=1}^{n} \ln \left(t_{i}\right)\right]-\frac{1}{m^{n}} \sum_{i=1}^{n} t_{i}^{n} \ln \left(\frac{t_{i}}{m}\right)=0
\end{array}\right.
$$

Where A is the total number of fault data and B represents the cumulati ve operation time of the system at the time of the fault. The final solution results are shown in Table 2 .

\section{TABLE II. PARAMETER ESTIMATION VALUE TABLE}

\begin{tabular}{|c|c|c|c|}
\hline$n_{1}$ & 0.4792 & $m_{1}$ & 1051.9 \\
\hline$n_{2}$ & 1.2923 & $m_{2}$ & 3036.0 \\
\hline$n_{3}$ & 12.7286 & $m_{3}$ & 5023.7 \\
\hline
\end{tabular}

\section{Triple Weibull Distribution Inflection-point Solution}

The life distribution of complex electronic system conforms to the bathtub curve law. According to the bathtub curve, there are three stages in its life cycle, and the transition time between the three stages is of particular concern to us. This turning point is called the critical time inflection point. For the three-segment Weibull distribution, such two key time inflection points are $t_{1}, t_{2}$, which are also the boundary points of the piece-wise function. According to the continuity of the function, we can get:

$$
\begin{aligned}
& R\left(t_{1}^{-}\right)=R\left(t_{1}^{+}\right), R\left(t_{2}^{-}\right)=R\left(t_{2}^{+}\right) \\
& f\left(t_{1}^{-}\right)=f\left(t_{1}^{+}\right), f\left(t_{2}^{-}\right)=f\left(t_{2}^{+}\right)
\end{aligned}
$$

Let,k=1,after derivation we can get:

$$
\begin{aligned}
t_{1} & =\left[n_{1} m_{2}^{n_{2}} m_{1}^{n_{1}} / n_{2}\right]^{1 /\left(n_{2}-n_{1}\right)} \\
t_{2} & =\left[n_{2} m_{3}^{n_{3}} m_{2}^{n_{2}} / n_{3}\right]^{1 /\left(n_{3}-n_{2}\right)} \\
k_{2}= & \exp \left[\left(1-n_{2} / n_{1}\right)\left(t_{1} / m_{2}\right)^{n_{2}}\right]
\end{aligned}
$$

$$
\begin{aligned}
& k_{3}=k_{2} \exp \left[\left(1-n_{3} / n_{2}\right)\left(t_{2} / m_{3}\right)^{n_{3}}\right] \\
& =\exp \left[\left(1-n_{2} / n_{1}\right)\left(t_{1} / m_{2}\right)^{n_{2}}+\left(1-n_{3} / n_{2}\right)\left(t_{2} / m_{3}\right)^{n_{3}}\right]
\end{aligned}
$$

Substituting the data in Table 2 into the above equation, The inflection point $\mathrm{A}$ at the critical time and the connection parameter B of each segment function can be calculated. Results are shown in Table 3.

\section{TABLE III. TIME INFLECTION POINTS AND CONNECTION} PARAMETER

\begin{tabular}{|l|l|l|l|}
\hline$t_{1}$ & $1.6738 \times 10^{3}$ & $k_{2}$ & 0.4554 \\
\hline$t_{2}$ & $4.3541 \times 10^{3}$ & $k_{3}$ & 0.1087 \\
\hline
\end{tabular}

\section{CONCLUSION AND ANALYSIS}

Substituting the values in Table 2 and Table 3 into equation (1), (2) gives the system failure rate expression (11) and the reliability expression (12).

$$
\begin{aligned}
& h(t)=\left\{\begin{array}{l}
4.5556 \times 10^{-4}(t / 1051.9)^{-0.5208}, 0<t<1.6738 \times 10^{3} \\
5.1232 \times 10^{-4}(t / 3036)^{0.2923}, 1.6738 \times 10^{3}<t<4.3541 \times 10^{3}(11) \\
0.003(t / 5023.7)^{11.7286}, t>4.3541 \times 10^{3}
\end{array}\right. \\
& R(t)=\left\{\begin{array}{l}
\exp \left[-(t / 1051.9)^{0.4792}\right], 0<t<1.6738 \times 10^{3} \\
1.2036 \exp \left[-(t / 3036)^{1.2923}\right], 1.6738 \times 10^{3}<t<4.3541 \times 10^{3}(12) \\
1.2032 \exp \left[-(t / 5023.7)^{12.7286}\right], t>4.3541 \times 10^{3}
\end{array}\right.
\end{aligned}
$$

Plot their function curve on the coordinate axis respectively, as shown in Figure 4,5.

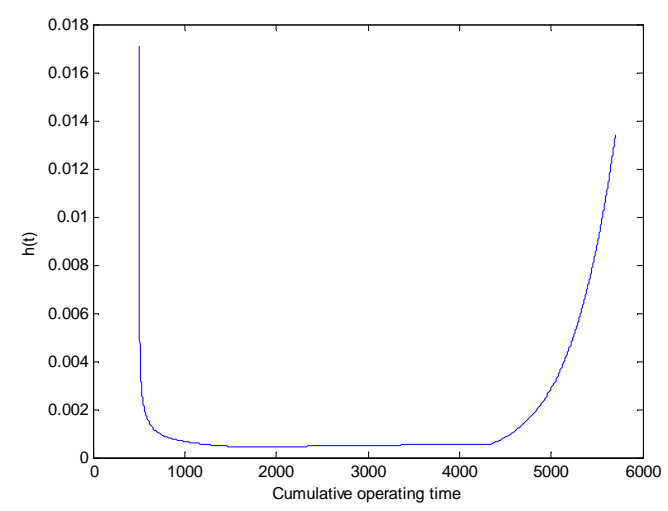

FIGURE IV. BATHTUB-TYPE FAILURE RATE CURVE 


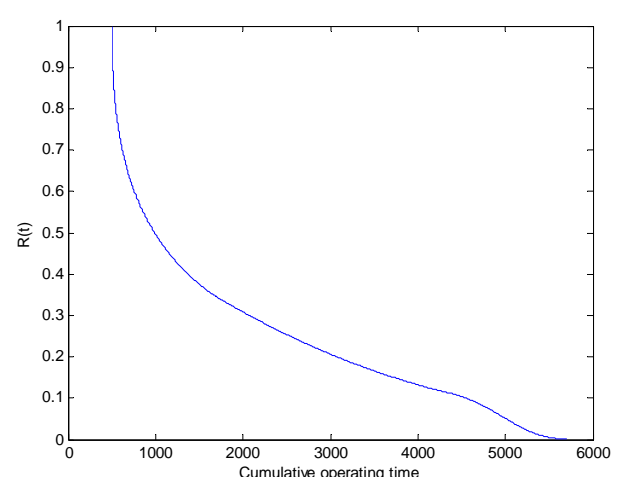

FIGURE V. RELIABILITY FUNCTION CURVE

It can be seen from Figure 4 that the current system is in a loss failure period. The duration of the loss failure period is unknown. The accidental failure period lasted about 4354 hours. As shown in the bathtub curve obtained, it can be known that the duration of the accidental failure period is not long, only about 2681h.After about 4354 hours of cumulative operation time, the system entered a loss failure period. Due to the requirements for the service life of the system and the different maintenance levels, there are two situations, such as "Repair as old" and "Repair as old". It may lead to a very long failure period of the system, making the boundary between the accidental failure period and the loss failure period not very clear.

It can be seen from Figure 5 that the reliability of the system is always reduced. The reliability function is a decreasing function of time. With the increase in cumulative operation time, reliability has been decreasing, which is in line with our subjective experience.

The simulation data is the system running up to 5500h. The simulation end time of the curves of Figure 4 and Figure 5 is $5700 \mathrm{~h}$. This prediction of the system failure rate and reliability of the next $200 \mathrm{~h}$ is reasonable, because it is based on a large amount of fault data during system operation.

\section{CONCLUSION}

This paper presents a method based on cumulative operation time data, using the triple Weibull distribution to describe the dynamic changes of the reliability and failure rate of individual system in various periods. It provides a feasible solution for predicting the reliability of individual system. It provides support for reliability parameters for the current state assessment of the system. At the same time, this method can also be used in the analysis of failure data for other similar military equipment or civilian system.

\section{REFERENCES}

[1] Mustafa Nadar and Fatih Kızılaslan, "Estimation of Reliability i-n a Multicomponent Stress-Strength Model Based on a Marshall-Olkin Bivariate Weibull Distribution,'IEEETrans.Rel, vol. 65.2016, pp.370-380,doi: 10.1109/TR.2015.2433258

[2] Wang Zheng and Xie Liyang, "Dynamic Reliability Model of Co mponents Under Random Load,”IEEETrans.Rel,vol.57,no.3,pp.4 74-479 ,2012.d oi:10.1109/TR.2008.928184
[3] Yu Liu and Chu-Jie Chen, "Dynamic Reliability Assessmen-t for Nonrepairable Multistate Systems by Aggregating Multilevel I mperfect Inspection Data,’IEEE Trans.Rel,vol.66,no.2,pp.281-297 20 17.do i:10.1109/TR.2016.2645840

[4] Yusuf Alper kaplan, "Determination of the best Weibull me-th ods for wind power assessment in the southern region of Tur key,”IEEE Trans.Rel,vol.11,no.1,pp.175-182,2017.doi:10.1049/iet-rpg. 2016.0206

[5] Y. Ding, M. J. Zuo, Z. Tian, and W. Li, "The hierarchical wei-gh ted multi-state k-out-of-n system model and its application for infr astructure management,”IEEE Trans.Rel,vol.59,no.3,pp.593-603,2010.

[6] Rosario Toscano and Patrick Lyonnet, “On-Line Reliability Predi-ct ion via Dynamic Failure Rate Model,”IEEE Trans.Rel.,vol.57,no.3,p p.452-457,2008.

[7] Yu Liu and Ming J. Zuo and Yan-Feng $\mathrm{Li}$ and Hong-Zhong $\mathrm{Hu}$ ang, "Dynamic Reliability Assessment for Multi-State Systems Utili zing System-Level InspectionData,’IEEE Trans.Rel,vol.64,no.4,pp.12 87-1299,2015.

[8] Ma Jiming and Wan Wei and Zeng Shengkui, "FFOP Prediction Method Based on Tub Line Failure Rate Function,”Journal of Aero nautics,vol.33,no.9,pp.1664-1670,2012.

[9] Zhang Genbao and Yang Xingyong, "Reliability Evaluation of Mac hining Center Based on Mixed Weibull Distribution,"Computer Ap plication Research, vol.32,no.11,pp:3278-3281,2015. 